\title{
Supplier-Switching Inertia and Competitive Asymmetry: A Demand-Side Perspective
}

\author{
Sali Li \\ David Eccles School of Business, The University of Utah, Salt Lake City, UT \\ Anoop Madhok \\ Schulich School of Business, York University, Canada \\ Gerhard Plaschka \\ Kellstadt Graduate School of Business, DePaul University, Chicago, IL \\ Rohit Verma \\ Service Operations Management, School of Hotel Administration, Cornell University, Ithaca, \\ NY 14853, e-mail: rv54@cornell.edu

\begin{abstract}
Building on strategic management, operations strategy, and supplier management literatures, this article presents a framework for supplier selection from the demand-side perspective. We highlight the role of a purchasing firm's switching inertia in the supplier selection process and demonstrate the usefulness of our framework for the industrial automation industry. Empirical data for this study was collected from 171 corporate and plant-level executives in pharmaceutical, chemical, and paper-and-pulp manufacturing industries in the United States. A series of Webbased individually customized discrete choice experiments asked the respondents to either switch to the new supplier or stay with the existing supplier. Based on the results of these experiments, we demonstrate the existence of switching inertia in the supplierselection process and discuss the managerial implications for incumbent and challenger supplier firms.
\end{abstract}

\section{Introduction}

Why is there competitive heterogeneity across suppliers in the same industry? How and when do buyers choose to switch suppliers? These topics are central to the strategic management and operations strategy field and at the core of the question, What are the origins of (sustainable) competitive advantage? (Hoopes, Madsen, \&Walker, 2003). Researchers from different perspectives (industrial organization, resource-based view [RBV], and supply chain management) provide important insights into this particular phenomenon. Industrial- 
organization scholars suggest that entry and/or mobility barriers create systematic differences across strategic groups (e.g., Caves \& Porter, 1977), whereas the RBV scholars assert that "there is no theoretical reason to limit mobility barriers to groups of firms" and propose that the existence of isolating mechanisms makes individual firms' "competitive positions stable and defensible" (Rumelt, 1984). The related literature in supply chain management explores the relationship between buyer and supplier firms as a multi-criteria decision-making problem (Dickson, 1966).

Although there are clear differences among these theories, they complement each other well (Wernerfelt, 1984; Porter, 1991). For instance, whereas industrial organization scholars would be more concerned with the existence of entry barriers (e.g., brand), RBV would be more concerned with the actual management of the brand, the superior managing of which would create an imitability barrier. The presence of such barriers acts to isolate incumbents from potential challenger suppliers who are on the other side of the barrier. Together, these two perspectives explain why there are competitive asymmetries across supplier firms in the same industry. Moreover, both of these theories make a common argument that incumbent suppliers protected by a barrier have a competitive advantage, and it therefore becomes critical for a potential challenger to overcome this barrier, thus neutralizing its disadvantage. Supply chain management literature, on the other hand, addresses the operational issues related to the relationship between buyer and supplier firms. It provides conceptual frameworks, empirical supports, and multicriteria decision-making techniques to model the interaction between buyer and supplier firms (e.g., Talluri \& Narasimhan, 2004, 2005; Narasimhan, Talluri, \& Mahapatra, 2006).

In recent years, with the increase in popularity of total quality management, concurrent engineering, lean manufacturing, and just-in-time inventory concepts, the supplier-selection question has become extremely important in the operations management literature. For example, as outsourcing becomes more important under these new paradigms, the supplierselection process does as well (Kannan \& Tan, 2002; Yan, Chaudhry, \& Chaudhry, 2003; Choy, Lee, \& Lo, 2003; Choy, Lee, Lau, Lu, \& Lo, 2004).With the rapid proliferation of information technology (IT), the importance of supplier management has been amplified during recent years (e.g., Fine, 1998; Hanfield \& Nichols, 1999; Kaplan \& Sawhney, 2000; Simchi-Levi, Kaminsky, \& Simchi-Levi, 2000; Hall \& Braithwaite, 2001). A number of empirical studies also show that operations managers indeed consider the role of supplier to be critical for superior business performance (e.g., Flynn, Schroeder, \& Sakakibara, 1994; Choi \& Hartley, 1996; Vonderembse \& Tracey, 1999; Gonz'alez, Quesada, \& Mora Monge, 2004). These studies emphasize the importance of cost, quality, delivery performance, and other criteria for selecting suppliers; however, can firms freely switch their suppliers just based on the above concerns? In other words, are there mechanisms, besides the ability to provide, for example, low cost and higher quality of products/services, isolating and distinguishing suppliers from each other? 
On close examination, it appears that much of the work on incumbent-challenger interaction has approached their rivalry from a supply-side perspective. For instance, Chen (1996), Cho, Kim, and Rhee (1998), and Shamsie, Phelps, and Kuperman (2004) attribute the asymmetry to the differences in resource endowments between incumbents and challengers. In a similar vein, D'Aveni's (1994) notion of hypercompetition assumes the abilities of rivals to rapidly imitate one another.

The emphasis on firms' supply-side factors implicitly suggests that challengers should strategically imitate the critical resources and capabilities possessed by incumbents. However, as Adner and Levinthal (2001) and Adner and Zemsky (2006) note, the focus on a supply-side perspective has largely resulted in a relative neglect of demand-side concerns. In this article, we explore challenger supplier strategy from a demand-side perspective, focusing on demand asymmetry within the buyer-supplier relationship. By challenger, we mean a prospective supplier who seeks to compete with an incumbent for a buyer firm's market share. By demand asymmetry, we mean buyers' biases in evaluating an identical offering between the incumbent suppliers and the challengers. In the context of this article, demand asymmetry is largely caused by the buyer organization's persistence with an existing relationship with incumbent suppliers, which we refer to as buyers' switching inertia.

Buyers' switching inertia has received relatively little attention in the study of challenger strategy, probably because the literature has tended to focus more on the ability of challengers to imitate an incumbent. In contrast, we raise the question, What if there are minimal returns to imitation? In such a case, seeking to imitate the resources/capabilities of a superiorly endowed incumbent would be a short-sighted strategy. It amounts to an unintelligent utilization of resources, because such a strategy would, at best, bring about an approximate competitive parity that would not suffice in the face of switching inertia. In other words, even if the challenger was able to imitate the incumbent and was, therefore, not limited by an abilitybased isolating mechanism, it may simply prefer not to do so due to poor returns from such a strategy. By isolating mechanisms, we refer to the strategy literature, especially the RBV (Rumelt, 1984; Wernerfelt, 1984). Isolating mechanisms function to make it difficult for other firms to easily imitate a focal firm, often because of the ambiguity and complexity of identifying and understanding the associated resources and capabilities. This can potentially extend the sustainability of a focal firm's competitive advantage. This, in effect, acts as a willingness-based isolating mechanism that becomes operational when a challenger does not have sufficient incentives to imitate the incumbent, that is, when there are inadequate returns to imitation.

We address the issue of demand asymmetry and its implications for incumbentchallenger rivalry in the context of the U.S. industrial-automation systems industry, because it provides a useful setting in which to conduct our study. Because the automation-systems industry has entered a mature stage and is characterized by a slow growth rate and capable competitors such as Emerson, Honeywell, Rockwell, and Siemens, the nature of competition in the industry is one of obtaining a greater market share rather than of creating new markets. 
Furthermore, the mature nature of the industrial-automation industry provides us with a stable set of competitor suppliers that are constantly trying to become preferred suppliers for manufacturing firms operating in a number of industries (e.g., automotive, food and beverage, paper and pulp, pharmaceutical, and chemical) by stealing market share from each other. Moreover, the suppliers in the automation-systems industry offer a wide range of products and different levels of sophistication and customization depending on buyers' specific needs. This allows us to better observe whether buyers' switching inertia varies across different buyer groups and, if so, what the implications are for challenger strategy.

Our study, based on survey-based empirical research using discrete choice analysis (DCA) (McFadden, 1986; Ben-Akiva \& Lerman, 1991; Louviere, Hensher, \& Swait, 2001; Verma, Thompson, Moore, \& Louviere, 2001), shows that buyers in the U.S. industrial-automation industry have significant switching inertia with respect to the existing supply relationships. In other words, the buyers demonstrate asymmetric evaluation toward the identical offerings of their incumbent suppliers and potential challengers. The buyer's switching inertia not only raises the bar for challengers, but also suggests that it would not suffice for challengers to provide the same or a marginally better level/mix of product/service as the incumbent. Rather, the challenger would, in all likelihood, have to develop different resources and capabilities from the incumbents and offer a different bundle of attributes that provides a significantly higher level of value than the incumbent.

By emphasizing the importance and existence of demand-side asymmetry and willingness-based isolating mechanisms, our article provides a different explanation of competitive heterogeneity across rivals in the same industry. The logical conclusion of our argument is that sustainable differences in the value provided by suppliers are partly due to the demand asymmetry. The article is organized as follows. First, we provide a review of supplierselection literature to show how our research fits with existing research. Next, we briefly summarize the causes of switching inertia. Then, through a discussion of the value matrix, we conceptually illustrate how and why buyers' switching inertia causes heterogeneity in value creation between incumbents and challengers. Finally, we use empirical evidence to illustrate the existence of switching inertia. Here, we use the DCA technique to present the demand side (i.e., buyer) perspective (Louviere \& Woodworth, 1983; McFadden, 1986; Verma, Iqbal, \& Plaschka, 2004), and we conclude our article with discussion and implications.

Prior to entering the next section we would like to point out one significant difference between the traditional DCA, which has seen applications in the operations management literature recently (e.g., Pullman, Verma, \& Goodale, 2001; Verma et al., 2001), and the one we used. Instead of merely asking the respondents to make choices between hypothetical suppliers (e.g., as illustrated by Verma \& Pullman, 1998), we actually compared their current suppliers with an experimentally developed new one and asked whether the respondents would like to switch to the new one or stay with the old. This exercise provides us with even more insight than the traditional DCA would have, as we not only get the information on the 
trade-offs between the different attributes, but also get insight into what the approximate switching costs are; in most cases the manufacturer will not switch over if the new supplier is only slightly better, but will only do so if the new supplier is significantly better and enough to offset the costs of switching. Additional details about the methodology are provided in the next sections.

\section{A Review of Supplier-Selection Literature}

In one of the early studies based on empirical data collected from 170 purchasing managers, who were members of the National Association of Purchasing Managers, Dickson (1966) identified more than 20 attributes that managers generally consider when choosing a supplier. Following this exploratory study, a great number of articles focused on supply chain management and supplier-selection criteria specifically.

A number of conceptual articles have been published in the last couple of decades: Cardozo and Cagley (1971), Sheth (1973), Dempsey (1978), Ansari and Modarress (1980, 1986), Monczka, Giunipero, and Reck (1981), Browning, Zabriskie, and Huellmantel (1983), Jackson (1983), Kraljic (1983), Treleven (1987), Burton (1988), Bernard (1989), Wagner, Ettenson, and Parrish (1989), Benton and Krajewski (1990), Chapman (1993), and several other authors emphasized the strategic importance of the supplier-selection process and evaluated the relative importance of quality, cost, delivery performance, and other supplier attributes in the supplier-selection process. Weber, Current, and Benton (1991) reviewed 74 articles discussing supplier-selection criteria and reaffirmed Dickson's (1966) finding that quality, cost, and delivery performance are most important. The interested reader is referred to a handbook of logistics and supply chain management (Brewer, Button, \& Hensher, 2001) for a general overview of supply chain management literature.

During recent years a number of empirical articles have been published that address supplier-selection issues in specific industries and/or present a comparison between two or more industries. For example, Pearson and Ellram (1995) examined supplier-selection and evaluation criteria in small and large electronic firms in the United States. Swift (1995) presented criteria used by purchasing managers in selecting single suppliers. Lambert and Adams (1997) presented an empirical review of attributes traditionally used by purchasing managers for supplier selection in hospital settings. Hirakubo and Kublin (1998) examined the purchasing behavior in the electronics components industry in Japan. Patton (1997) addressed trade-offs in individual and joint selection decision making in the industrial-supplier-selection process. Ittner and Larcker (1999) examined the relationship among supplier selection, monitoring practices, and organizational performance. Carter and Jennings (2004) studied the corporate social responsibility in the purchasing function context. Lin, Chow, Madu, Kuei, and Yu (2005) showed that quality-management practices are significantly correlated with supplierselection strategies. And finally, González et al. (2004) investigated the importance of supplier selection in the quality of the final product and determined that it is in fact the most significant variable. 
Most often a manufacturer has multiple suppliers from which to choose and has to make a decision based on multiple variables. To accommodate this decision, Weber and Current (1993) proposed a multi-objective approach to supplier selection that provides a useful decision-support system for a purchasing manager faced with multiple suppliers and trade-offs such as price, delivery reliability, and product quality. Alternatively, Pearn, Wu, and Lin (2004) developed a process capability index ( $\mathrm{Cpm}$ ), which collapses all decision variables into a single index, simplifying the supplier decision. Perhaps the most used decision-support system for supplier selection is the Analytical Hierarchy Process (AHP). An application of the AHP to the supplier-selection process was first described by Barbarosoglu and Yazgac (1997), and it has subsequently been compared with the Total Cost of Ownership method (Bhutta \& Huq, 2002), applied on vendor selection (Chan, 2003), used to tackle multi-item/person/criterion decisions (Chan \& Chan, 2004), and used along with the Gray rational scale by Tseng and Lin (2005) to rate suppliers. In a series of articles Talluri and coauthors have presented a number of multicriteria decision making models (primarily based on various operations-research techniques) such as Data Envelopment Analysis (Talluri \& Narasimhan, 2004, 2005).

Recently a number of simulation studies with a focus on the supplier-selection process have also appeared. Crama, Pascual, and Torres (2004) formulated a nonlinear 0-1 programming problem with complex quantity discounts offered by different suppliers and alternative product recipes. Cakravastia and Takahashi (2004) created a simulation model to determine which supplier to select for business and the volume assigned to each of those suppliers. Finally, Basnet and Leung (2005) created a simulation model to determine what products to order in which quantities from which suppliers in which periods to satisfy a given demand stream.

It is desirable for firms to select a supplier that excels on most of the supplier evaluation criteria. At the same time, it is unlikely that any one supplier can excel on all or multiple evaluation criteria at a reasonable cost. Consequently, firms must trade off among price, quality, and other value-added features when choosing suppliers for key components and raw materials. To address this complex multicriteria managerial decision-making problem, a variety of supplier evaluation and selection models have been developed. For example, Vokurka and Choobineh (1996) developed a prototype expert system for evaluation and selection of potential suppliers. Patton (1996) explored the impact of human judgment models in combination with multi-attribute supplier-evaluation methods. Rosenthal and Zydiak (1995) and Sarkis and Semple (1999) addressed the issue of bundling multiple stock items on purchase costs and subsequently on supplier selection. Karpak, Birsen, Rammohan, and Kumcu (1999) presented a visual interactive goal programming procedure that assists purchasing teams in the supplier-selection process. Petroni and Braglia (2000) proposed an alternative decision model based on purchasing managers' periodic evaluation of suppliers, using a principal components analysis. Masella and Rangone (2000) proposed a contingency approach for supplier selection depending on the timeframe and the content of cooperative customer/supplier relationships, and Eltantawy, Sharland, and Giunipero (2003) examined the role of cycle time in supplier 
selection and performance. Braglia (2000) developed a data envelopment analysis-based model for formulating sourcing strategies in a changing marketplace. Degraeve, Labro, and Roodhooft (2005) proposed a mathematical programming approach known as Total Cost of Ownership perspective, which allegedly outperforms other multicriteria supplier-selection models and combined this later with Activity Based Costing (Roodhooft \& Konings, 1997) in a case study.

In summary, supplier-selection literature boasts an abundance of conceptual and review articles, empirical research, decision-support systems, simulation studies, and applications of multicriteria decision-making techniques. We contribute to this stream of research by illustrating the usefulness of DCA in evaluating the relative impact of various value-added features in the supplier-selection process while considering switching inertia. While the multicriteria decision-making models presented previously here provide important insights within the context they study, they do not explicitly consider or quantify switching inertia between an incumbent and challenger firm. Furthermore, as mentioned earlier, we did not use a traditional and simplistic form of DCA in which the decision maker is asked to choose between two or more hypnotic alternatives. We customized our survey instrument for each individual respondent such that he/she had to choose to either stay with the existing supplier or switch to a new experimentally generated but realistic supplier. Our approach, therefore, can accurately quantify switching inertia with respect to various attributes of incumbent and challenger supplier firms. Additional details about switching inertia are provided in the next section.

\section{Switching Ineratia: A Strategy Perspective}

Although the causes of switching inertia have been well documented in the strategy literature, few efforts (Rumelt, 1984; Hoopes et al., 2003, for an exception) have been devoted to understanding how buyers' switching inertia causes heterogeneity among close rivals. As mentioned, in the context of our article, switching inertia refers to the organizational persistence with an existing relationship with incumbent suppliers. Three main factors affect buyer choice: (i) the costs to buyers of investing in specialized assets in order to adapt to the incumbent supplier's product, (ii) the idiosyncratic routines and accrued relational rents between buyers and incumbent suppliers, and (iii) the buyers' organizational inertia. We elaborate on these in the following.

\section{The Costs of Specialized Investment}

As Lieberman and Montgomery (1988) note, buyers often must make specialized investments in order to adapt to a supplier's product. Such investments become a major source of first-mover advantages for the incumbent supplier and, from a challenger's point of view, affect the buyer's choice of suppliers to a nontrivial degree.

Note that only the costs associated with specialized investments rather than the total amount of fixed costs affect buyer choice. If the buyer's investment is not specific to the incumbent suppliers, the buyer will not have extraordinary concerns in supplier choice 
(Williamson, 1985), and thus there will be less asymmetry in the choice between incumbent and challenger suppliers. For instance, assume that there are two buyers: one is using standard software to manage its inventory system, while the other is using unique software provided by and designed only for its incumbent supplier. Even though the former buyer might incur higher costs to pursue the standard software than the latter buyer, it is more likely to accept and switch to another's products due to the compatibility of its infrastructure. Hence, the specificity of the investment plays a key role in determining the extent of buyer switching inertia.

\section{$\underline{\text { Idiosyncratic Routines and Relational Rents }}$}

Demand asymmetry can also stem from the idiosyncratic routines and the valuable relationship between buyers and incumbent suppliers. Repeat interaction over time results in efficiency-enhancing routines being formed. These routines could range from simple ones, such as whom to contact in case of difficulties, to more complex ones, such as knowledge-sharing routines. Also, successful repeat interaction provides a basis for trust (Gulati, 1995), in which case the firm might not perceive the need for a high level of protective safeguards or monitoring of the supplier, thus lowering costs, as well as may be more willing to engage in value-creating initiatives.

Dyer and Singh (1998) elaborate on how trust and intertwining routines stemming from past relations can help firms accomplish more through their relationship with a particular supplier. They consider this to be the source of relational rents, defined as the "supernormal profit jointly generated in an exchange relationship" (Dyer \& Singh, p. 662). Such relationships tend to be rare, valuable, inimitable, and nonsubstitutable (Barney, 1991). As a result, firms develop switching inertia, making it difficult for latecomers to directly substitute for the incumbent suppliers.

\section{Buyer's Organizational Inertia}

Besides the considerations of reducing specific investment costs and enhancing relational rents, the buyers' own organizational inertia can also distort the choice between suppliers, thus causing disadvantages for the challenger. As Rumelt (1995) noted, inertia, defined as the "persistence of inefficient forms and practices" (p.103), is one of the major problems facing firms and is particularly the norm in big ones. Whereas inertia may not be so costly when the firm is pursuing efficient practices, it becomes so when the practices are no longer so efficient. Inertia occurs because of bounded rationality, path dependence, and the embeddedness of firm routines. Inertial tendencies, along with their opposing counterparts (i.e., momentum), result in managerial myopia and resistance to change (Rumelt, 1995). In the extreme, myopia can result in the systematic continuation and pursuit of the existing strategy, despite the presence of negative signals.

\section{Value Creation and Interfirm Differences}


To anticipate our subsequent arguments, we conceptually illustrate how and why buyers' switching inertia causes heterogeneity in value creation between incumbents and challengers and what this means for a challenger's strategy. We adopt the widely accepted view that the essence of strategy is the search for competitive advantage. In this regard, Porter (1996) makes a distinction between operational effectiveness and strategic positioning. Operational effectiveness means performing similar activities better than rivals, whereas strategic positioning means performing different activities from rivals or performing similar activities in different ways. From an operational-effectiveness standpoint, a challenger will benchmark and attempt to outperform the incumbent following a similar value configuration. However, assuming that the incumbent is in that position primarily because it performs a particular set of activities at the competitive frontier, any improvement by the challengers would probably not suffice to compensate for some significant level of switching inertia. Moreover, seeking to outperform the incumbent following its activity configuration also has the disadvantage of competing with the incumbent on its own terms and on terms that may depart from the challenger's own competencies. Path dependence makes this more difficult to accomplish.

On the other hand, strategic positioning refers to choosing a different activity configuration to deliver a unique value mix. This may be more in tune with a challenger's own competencies (or provide it with an opportunity to develop them) and would make it more difficult for an incumbent rival to respond due to path dependence.

To restate the point, a firm must offer greater value to a customer to attain competitive advantage over rivals. This would be difficult through a strategy of operational effectiveness when switching inertia is present to a nontrivial degree. We illustrate this in the following through an elaboration of the value matrix. The value matrix is an extension of the concept of value chain but one that is more suitable as a tool to explain the significance of switching inertia. For example, concern with comparative costs alone ignores quality. Ability to offer greater quality at the same cost or same quality at lower cost vis-a-vis other firms enables the firm to deliver superior value, which then translates into competitive advantage. One can expand this concept into $n$-dimensional space, with each dimension representing one of the components of value (e.g., speed, flexibility, reliability, and so on), each of which can be decomposed into further subelements (e.g., for speed: speed of delivery, speed of new-product development, manufacturing lead time, etc.).

Value can thus be conceptualized as a dynamic composite comprising an array of characteristics, where the importance or relative weight of the various components or subcomponents in the mix is context dependent and shifts around depending on the particular situation in the relevant environment. For example, time to market may be very valuable in the computer industry but less so in the steel industry. The point is that various activities, or combinations of activities, enjoy differing premium levels in different environments (or during different periods in the same environment). 
A simple example can help demonstrate the notion of value matrix. Suppose the firm's value proposition is composed of a particular vector $A$, which is composed of speed (A1), price $(A 2)$, service (A3), innovation $A(4)$, with a weight of, for instance, 15, 30, 20, and 35\%, respectively (adding up to $100 \%$ ). Each of these is composed of a subvector: speed of delivery (a11), speed of new product development (a12), manufacturing lead time (a13) . . . (with each subvector adding up to the value of the primary vector component).

In Table 1we present the major vector, A, of three mock firms' value matrices. One is the incumbent and the other two are challengers. The ideal value combination (i.e., the weight that is assigned to each attribute) is the most effective approach to satisfy buyers in this industry. In this mock market segment, we assume that buyers value the feature of innovation most (i.e., weight 35 out of 100) and the attribute of speed least (i.e., weight 15 out of 100). In this example, Incumbent offers buyers 78 utilities out of 100. Challenger 1 outperforms Incumbent in innovation, the most weighted attribute. However, although Challenger 2 is effective in speed, the least weighted attribute, this cannot give it enough leverage over Incumbent. Similarly the components of major vector A can be divided into subvectors as described for speed in Table 1.

\begin{tabular}{lccccc}
\hline Value Vector $\rightarrow$ & Speed (A1) & Price (A2) & Service (A3) & Innovation (A4) & Sum \\
\hline Ideal combination & 15 & 30 & 20 & 35 & 100 \\
Incumbent & 10 & 25 & 18 & 25 & 78 \\
Latecomer 1 & 11 & 24 & 16 & 33 & 84 \\
Latecomer 2 & 12 & 22 & 16 & 25 & 75 \\
& & & New Product & & \\
& & Delivery & Development & Manufacturing & \\
Speed Subvector (A1) $\rightarrow$ & Speed (A11) & Speed (A12) & Lead Time (A13) & Sum \\
\hline Ideal combination & 5 & 5 & 5 & 15 \\
Incumbent & 5 & 4 & 3 & 10 \\
Latecomer 1 & 5 & 2 & 4 & 11 \\
Latecomer 2 & 3 & 5 & 4 & 12 \\
\hline
\end{tabular}

Table 1: An illustration of value matrix.

The data presented inTable 1 suggests that, because Challenger 1 outperforms Incumbent (84 vs. 78), the buyer could switch to Challenger 1 . On the other hand, the buyer would not switch to Challenger 2 because this supplier does not provide superior value compared to Incumbent (75 compared to 78). This assessment of switching, however, assumes that the buyer has none or negligible switching inertia. On the other hand, if significant switching inertia exists, then the buyer might not be motivated to switch to Challenger 1 even though the latter provides higher value. For example, let us assume that inertia is 15 units on the value matrix scale. Therefore, when considering switching to an alternate supplier, the 
buyer will compare the value provided by Incumbent + switching inertia which is 93 units (78+ 15). Because both challengers offer values less than 93 , the buyer will perceive itself to be better off staying with Incumbent. This means that both the challengers will have to develop additional capabilities to overcome the inertia barrier before they can be seriously considered by the buyer as alternatives to Incumbent by the buyer. The above analysis is visually presented in Figure 1.

The value matrix is a conceptual tool that allows us to hypothetically illustrate incumbent-challenger interaction in the same industry. The relevance that the value matrix has to our argument is that it provides an opportunity for close rivals to compete with a different set of tools in its arsenal. In the next section, we empirically test the existence of switching inertia (and consequent demand asymmetry) and analyze its implications for challenger strategy.

\section{Research Methods}

For reasons described in the Introduction and, additionally, due to data access available to our research team, we selected the industrial-automation-systems industry as the context for our analysis. Industrial-automation products are a complex mix of hardware and software systems including programmable logic controllers, various input-output devices, and other

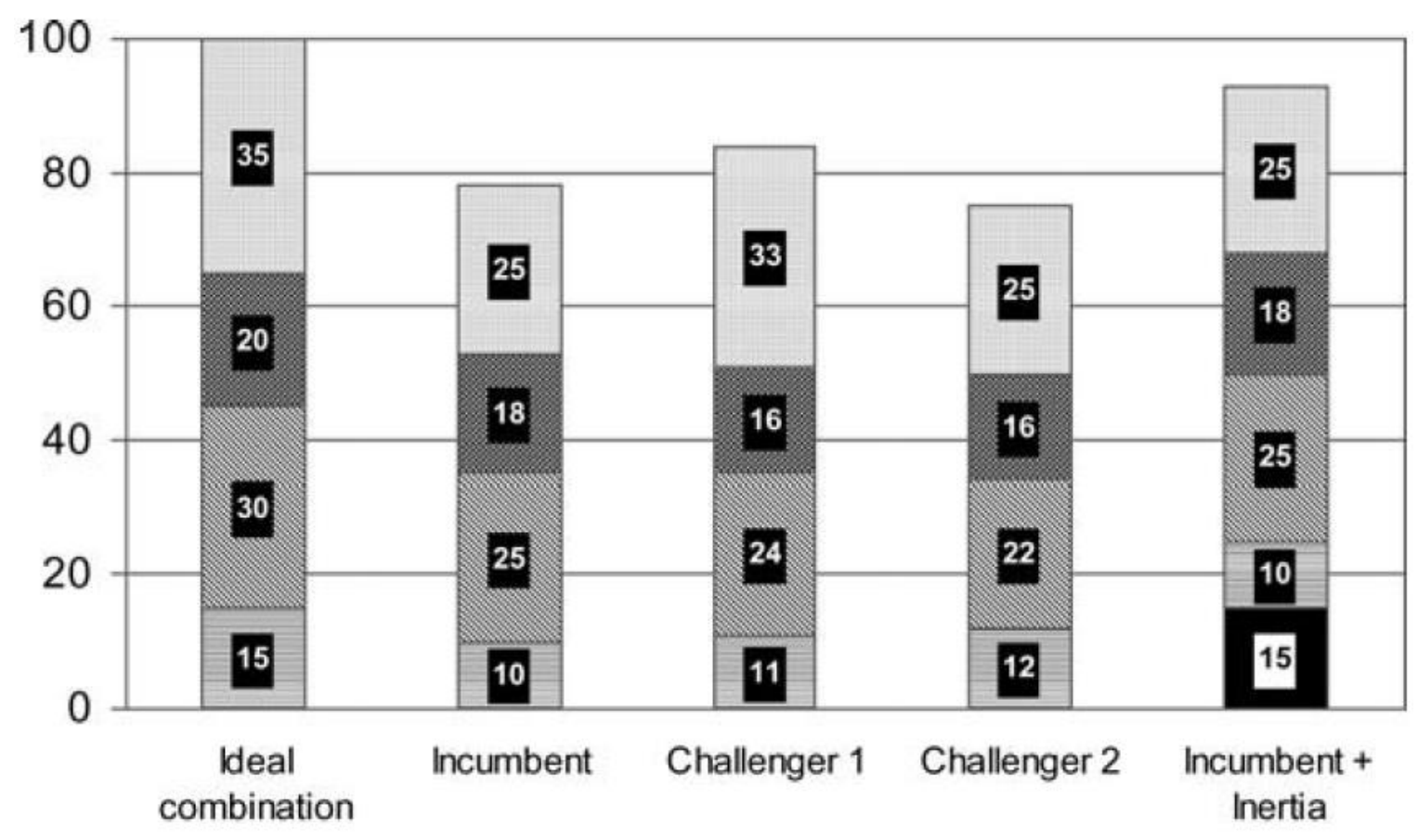

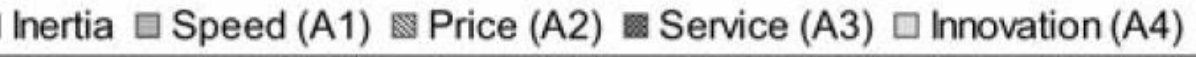

Figure 1: A graphical representation of value matrix. 
technical components necessary to automate the processes within manufacturing plants. Industrial-automation systems cost a million U.S. dollars or more, depending on the specific application. Dominant providers for industrial automation systems include Rockwell in the United States and Siemens in Europe, along with a number of competitors. However, Rockwell and Siemens each enjoy dominant positions (more than $50 \%$ market shares) in their respective home markets, according to various industry publications.

\section{Approach}

In order to understand switching inertia in the supplier-selection process, one must consider the relative weights that buyers attach to various characteristics of their current supplier with respect to other competitors. When faced with a supplier selection-choice task, decision makers (corporate executives) are likely to consider features/characteristics of their current suppliers with which they are already familiar and also new features/characteristics that potential suppliers make available to them (Anderson, 1971; Bettman, Capon, \& Lutz, 1975; Lynch, Marmorstein, \& Weigold, 1988). At the same time, it is generally not possible for any supplier to excel on all criteria considered by the buyer at the best possible price.

Therefore, the buyer has to make trade-offs when faced with a choice between staying with the existing supplier or switching to a new supplier. Hence we used DCA, which is an effective method for determining the relative weights assigned by decision makers to components of decision criteria (Louviere \&Woodworth, 1983; McFadden, 1986; Ben-Akiva \& Lerman, 1991).

DCA provides a systematic way to identify the implied relative weights and trade-offs revealed by the choices of decision makers. DCA has been used to model choice behavior in many business and social science fields, and introductions to and extensions of DCA can be found in sources cited here previously and others, such as Hensher and Johnson (1980), Guadagni and Little (1983), and Green and Krieger (1996). Naturally, DCA is not the only approach that has been used to understand and model consumer and managerial decision making, but it has proven particularly valuable in many hundreds of applications since its introduction by McFadden (1986) and development of associated empirical experimental technique by Louviere and Woodworth (1983) (Professor McFadden, one of the original theoretical contributors to the choice modeling approach, received a Nobel Prize in economic sciences in 2000).

Econometric models developed from a DCA study can link determinant supplier attributes to decision makers' (e.g., buyers') preferences. Therefore, by describing a supplier in terms of appropriate attributes of industrial-automation systems, DCA can be used to predict market impact of competitors in a given environment. In particular, research suggests that, after acquiring information and learning about possible alternatives (e.g., current and new potential suppliers), decision makers define a set of determinant attributes to use to compare and evaluate alternatives. They then form impressions of each alternative's position on the determinant attributes; value these attribute positions vis-'a-vis one another (i.e., make tradeoffs); and combine the attribute information to form overall impressions of each alternative. 
It is now well known that, within the discrete choice framework, the conditional probability of choosing an alternative in a choice set can be expressed as a multinomial logit (MNL) model (McFadden, 1986). The MNL model is expressed as

$$
\text { (1) }\left(P_{j} \mid C_{n}\right)=\frac{e^{V j \mu}}{\sum_{k=1}^{n} e^{V k \mu}}
$$

where $V_{j}$ represents the systematic component of utility of alternative $j$. MNL is a member of the family of Random Utility models, which assume that the utilities of real interest are latent, unobservable constructs. These latent utilities can be represented by a systematic (or explainable) component $\left(V_{j}\right)$, which can be estimated, and a random (or unexplainable) component, which, in the case of MNL, is independent and identically distributed according to a Gumbel distribution with a scale parameter $\mu$. We can decompose any product, service, or decision criterion (e.g., supplier) into a bundle of attributes and represent an alternative's systematic utility as follows:

$$
\text { (2) } V_{j}=\sum_{a \in A} \beta_{a} X_{a j},
$$

where $\beta_{a}$ is the relative utility associated with attribute $a$ (e.g., a specific supplier characteristic such as speed, innovation, or price).

Execution of DCA requires careful design of product/service profiles (e.g., a specific industrial-automation supplier) and choice sets (e.g., a group of automation suppliers) in which two or more alternatives are offered to decision makers (e.g., buyers), who are asked to evaluate the options and choose one (or none). Each respondent in a DCA experiment receives several choice sets to evaluate (e.g., 8-32 sets) with two or more hypothetical services to choose from in each set. The design of the experiment is under the control of the researcher and, consequently, the decision makers' choices (dependent variable) are a function of the attributes of each alternative, personal characteristics of the respondents and unobserved effects captured by the random component (i.e., unobserved heterogeneity or omitted factors) (Louviere \& Woodworth, 1983; Verma, Thompson, \& Louviere, 1999).

DCA applications based on choice experiments typically involve the following steps: (i) identification of determinant attributes, (ii) specification of attribute levels, (iii) experimental design, (iv) presentation of alternatives to respondents, and (v) estimation of the choice model. Past studies have shown that, in general, the market predictions generated from the statistical models based on DCAs are extremely accurate (e.g., Verma et al., 2001). To the best of our knowledge, this methodology has not been introduced to the supplier-selection literature with the exception of a simple illustration by Verma and Pullman (1998). Given the focus of this study, it seems appropriate to apply DCA to explore the challenger strategy from the demandside perspective.

\section{Experimental Supplier Attributes}

Louviere and Timmermans (1990) suggest that one should consider the following when 
a list of attributes for discrete choice experimental design: (i) Is it necessary to include an exhaustive list of all salient attributes? and (ii) Which attributes can be retained, recombined, or reexpressed to keep the set of attributes as nonredundant and as small as possible to make the experiment tractable but realistic? They suggest that great care must be taken to ensure that all (or at least as many as possible) of the determinant decision attributes are identified and expressed in terms understood by the decision makers to be studied. They recommend use of qualitative surveys, interviews, case studies, and/or focus groups to identify a set of relevant attributes along with reviews of practitioner and academic literature.

In order to develop a comprehensive list of industrial-automation-supplier attributes, we first started with the existing academic and practitioner/managerial literature (summarized earlier) and then collected in-depth qualitative information from plant-level and corporate senior executives of both buyer and supplier organizations responsible for supply chain/purchasing, engineering, product development, production, and financial responsibilities. We conducted a number of interviews and group discussion sessions in addition to reviewing both academic and practitioners literature related to the topic. Based on information collected from 27 executives, we developed an initial list of supplier attributes and levels. This list was distributed to all of the executives and also to five new executives for additional feedback and edits. Based on their responses, the list of attributes was modified for content, wording, and comprehensiveness. After four similar iterations, the final list of supplier attributes/levels was considered acceptable by most executives and by members of our research team.

\begin{tabular}{lcccc}
\hline Innovativeness & Integration & Price & $\begin{array}{c}\text { Supplemental } \\
\text { Service }\end{array}$ & $\begin{array}{c}\text { Training } \\
\text { and Support }\end{array}$ \\
\hline $\begin{array}{l}\text { Technical } \\
\text { Innovation (3) }\end{array}$ & $\begin{array}{c}\text { Industry Specific } \\
\text { Integration } \\
\text { Experience (4) }\end{array}$ & $\begin{array}{c}\text { Price of the } \\
\text { automation } \\
\text { solution (4) }\end{array}$ & $\begin{array}{c}\text { Service } \\
\text { Engineer (4) }\end{array}$ & Training Options (4) \\
Interoperability (4) & $\begin{array}{c}\text { Ease of system } \\
\text { programming (3) }\end{array}$ & $\begin{array}{c}\text { Cost } \\
\text { optimization (4) }\end{array}$ & $\begin{array}{c}\text { Project } \\
\text { Services (4) }\end{array}$ & $\begin{array}{c}\text { Application } \\
\text { Engineer }\end{array}$ \\
& Automation & Performance & Distribution & Involvement (4) \\
Automation & Integration & guarantee (2) & Services (2) & Resources (4) \\
Focus (3) & services (3) & & & Local Sales \\
Product Breadth & IT integration (3) & & & Support (4) \\
\hline
\end{tabular}

Note: The numbers in parentheses indicate levels for each attribute.

Table 2: Experimental attributes classified within three broad categories

Table 2 lists selected supplier attributes, their levels, and their classification into five broad conceptual categories (innovativeness, integration, price, supplemental service, and training and support). The innovativeness category contains four attributes (technical innovation, interoperability, automation focus, and product breadth), which collectively 
constitute the commonly accepted industry description of innovation in the automationsystems industry. The integration category contains four attributes (industry-specific integration experience, ease of system programming, automation-integration services, and IT integration), which collectively represent features that allow automation systems to be fully connected with various manufacturing processes. The price category includes three attributes (price of the automation system, cost optimization, performance guarantee), which determine cost of ownership for a specific automation system. The fourth category, supplemental services, includes three types of add-on services (service engineer, project services, and distribution services), which can be potentially offered by the automation-systems supplier. The final category is labeled training and support, which includes four attributes (training options, application engineer involvement, primary contact resources, and local sales support). Each of these attributes was described between two to four realistic levels. For example, the three levels for function integration were none, basic integration, and comprehensive integration. Similarly, technical innovation was described as either superior to, same as, or lagging competition. While the descriptions of levels of attributes are specific to the automationsystems industry, the conceptual categories and most of the attributes described here are fairly general.

\section{Experimental Design}

As described in Table 2, a total of 18 experimental attributes, each with two to four levels, were identified after the qualitative research stage. As is a common practice in DCA with a large number of attributes, we used fractional factorial design procedure to develop 128 orthogonal supplier profiles, which could allow estimation of main effects for all attributes (Louviere, 1988).To enhance the realism of the task, a full-profile approach was used in presenting the choice sets (Green \& Srinivasan, 1990), that is, each profile shown to the respondents simultaneously described some combination of all the attributes.

An example of fractional factorial design applied to a simple DCA is presented by Verma et al. (1999). In that application the authors were interested in studying customer choice of pizza delivery companies, and they only considered eight attributes, each with two levels. Because the number of attributes and their levels are quite large in our study compared to Verma et. al.'s (1999) application, we are not presenting the detailed experimental-design matrix within this article (the experimental-design matrix will essentially contain 18 orthogonal columns of numbers in 128 rows). At the same time, we would like to assure the readers that the experimental-design procedure followed was quite similar and consistent with other works that have used DCA for problems with similar complexity (e.g., Pullman \& Moore, 1999).

As mentioned earlier, the 128 experimental supplier profiles are sufficient to estimate main effects of each attribute included within the study. It is unrealistic, however, to assume that a potential respondent can (or will) systematically evaluate 128 new suppliers in the limited time available to them. Therefore, we used a follow-up experimental-design procedure known as blocking. Blocking refers to the task of splitting the core set of 128 experimental 
profiles into subgroups that are statistically equivalent. By statistical equivalence, we imply that each level of each attribute appears an equal number of times within each subgroup. We would like to recommend that the reader refer to the textbook by Louviere et al. (2001), which devotes three chapters to designing discrete choice experiments (including fractional designs and blocking) in an easy-to-understand format. Other related references for experimental design and DCA applications are summarized in Verma and Plaschka (2005).

Using the procedure described above, the resulting 128 experimental supplier profiles were divided into eight statistically equivalent sets of 16 profiles each. Later each respondent was randomly assigned to one of the eight sets and was asked to respond to 16 choice tasks as described below.

Because the objective of our study was to assess switching inertia, the choice task was formulated as a comparison between a respondent's current supplier and an alternative supplier generated experimentally. To be able to implement such a choice task it was necessary to first ask the respondent to describe the levels for each experimental attribute for their current supplier. Note that the description of the current supplier can be unique to each respondent. Therefore, the resulting choice experiment was unique to each respondent.

Implementation of a current versus a new supplier choice experiment requires that we keep track of respondents' answers and then incorporate them within the choice experiment. We developed a database-driven Web-based survey system to keep track of individuals' responses about their current supplier and then later presented them alongside the experimentally generated new supplier profiles. A sample supplier-selection-choice exercise is presented in Figure 2.

We pretested the choice task with the group of executives who participated in the qualitative research and also with ten new respondents. Based on their feedback, the method and layout of the survey were slightly modified to enhance clarity and realism of the choice tasks. During the pretesting phase we analyzed the data collected from the respondents to assess whether they found the choice experiments to be too complex. If indeed the respondents found the survey to be complex, we would not have seen any identifiable pattern in the data (i.e., the error in estimated models will be much higher compared to the explained variance). In addition to testing the statistical properties of the estimated models, we also randomly contacted six of the pretest respondents and asked them directly whether they found the supplier-selection-choice task to be too complex. We were very pleased when the respondents noted that they did not have trouble understanding or comprehending the choice experiments. We specifically asked them if representation of a supplier on 18 attributes was confusing. The common response to this question was that "supplier selection is inherently a complex problem and we have to constantly deal with a large number of supplier attributes."

In addition to the supplier-selection-choice task, the survey instrument included demographic questions about the respondents (e.g., age, gender, education, work experience) 
and background information about the respondents' organizations.

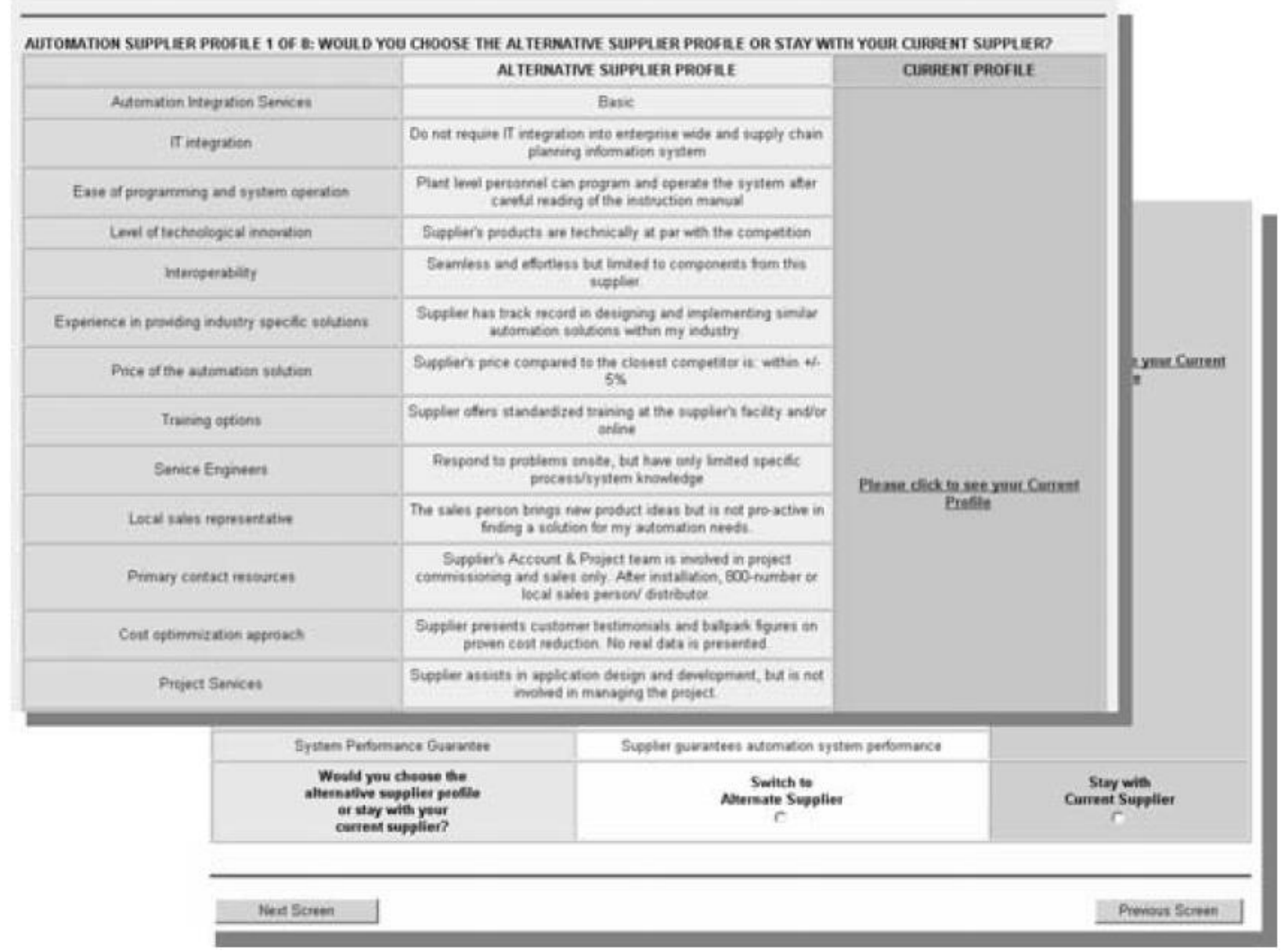

Figure 2: Sample supplier selection computer-based choice screen.

\section{Sampling and Data Collection}

The survey was sent to executives in three different types of manufacturing industries that buy and use industrial-automation products in their factories. These were chemical, pharmaceutical, and paper-and-pulp manufacturing industries. Senior executives with purchasing/supplier-selection responsibility, such as plant managers, operations managers, vice presidents for manufacturing/supply management (or similar) were contacted by telephone and were asked to participate in the survey. The participants had the opportunity to receive a copy of the summarized results and monetary incentives by participating in the survey. After recruiting potential respondents by telephone, we provided URLS and unique passwords for the survey. Respondents who did not answer the survey within the next two weeks were reminded by both telephone and e-mail. The resulting response rate for all of the executives who agreed to participate in the survey was approximately $65 \%$. Note that the data collection for this project was quite expensive and a rather time-consuming process. In addition, the design and development of individually customizable choice experiments (current vs. newsupplier) 
required extensive programming. To check for response bias we compared responses for early and late responders. Because we only had contact information about the nonrespondents, we could not statistically compare the demographics characteristics of respondents and nonrespondents. At the same time, the distribution of organizations and respondents is quite broad (based on several criteria such as size, geographical region, education, etc.) and, therefore, appropriate for the purposes of our study. Table 3 contains sample demographics. To fulfill the requirements of the confidentiality agreement with the survey respondents we were only to release sample sizes, respondent's position (either a plant or corporate executive responsible for supplier management, and the name of the company's primary automation supplier).

\begin{tabular}{|c|c|c|c|c|c|c|}
\hline \multirow{2}{*}{$\begin{array}{l}\text { Number of Respondents } \\
\text { Automation supplier }\end{array}$} & \multicolumn{2}{|c|}{$\begin{array}{c}\text { Pharmaceutical } \\
60\end{array}$} & \multicolumn{2}{|c|}{$\begin{array}{c}\text { Paper \& Pulp } \\
48\end{array}$} & \multicolumn{2}{|c|}{$\begin{array}{c}\text { Chemical } \\
63\end{array}$} \\
\hline & Rockwell & $30.0 \%$ & GE & $4.2 \%$ & GE & $4.8 \%$ \\
\hline & Siemens & $20.0 \%$ & Rockwell & $33.3 \%$ & Rockwell & $14.3 \%$ \\
\hline & Schneider & $3.3 \%$ & Siemens & $4.2 \%$ & Siemens & $4.8 \%$ \\
\hline & Emerson & $36.7 \%$ & Schneider & $4.2 \%$ & Schneider & $3.3 \%$ \\
\hline & Honeywell & $6.7 \%$ & Emerson & $36.7 \%$ & Emerson & $33.3 \%$ \\
\hline & Invensys & $3.3 \%$ & Metso & $8.3 \%$ & Invensys & $38.1 \%$ \\
\hline & & & Honeywell & $12.5 \%$ & & \\
\hline & & & Invensys & $12.5 \%$ & & \\
\hline & & & $\mathrm{ABB}$ & $12.5 \%$ & & \\
\hline \multicolumn{7}{|l|}{ Managerial position } \\
\hline Plant management & & $73.3 \%$ & & $66.7 \%$ & & $61.9 \%$ \\
\hline Corporate executive & & $26.7 \%$ & & $33.3 \%$ & & $38.1 \%$ \\
\hline
\end{tabular}

Note: Total sample $\mathrm{N}=171$.

Table: Sample characteristics.

\section{$\underline{\text { Analysis }}$}

The primary analysis approach associated with DCA is the estimation of the MNL models based on a maximum likelihood estimation technique (Equations (1) and (2)). We used the LIMDEP program to estimate supplier-selection MNL models for each of the three industrial sectors from which data were collected. All of the estimated models were found to be statistically significant at the $5 \%$ level, and the necessary goodness-of-fit measures (loglikelihood ratio; McFadden's $\rho^{2}$ ) show excellent statistical properties (Ben-Akiva \& Lerman, 1991; Louviere et al., 2001). Similar to ordinary least square regression, MNL models are derived by estimating $\beta$ weights for all independent variables included within the model. The difference between the highest and lowest levels of an attribute represents the main effect of the attribute on the dependent variable (supplier choice). Furthermore, according to Swait and Louviere (1993), the scale parameters ( $\mu$ in Equation (1)) within each estimated model are different from each other because of differences in inherent variability within different 
samples. Therefore, as recommended by Swait and Louviere (1993), we rescaled the models using a chi-square $\left(\chi^{2}\right)$ test based procedure so that estimated weights across models can be compared to each other. For ease of reading, the discussions of results in this article are presented in graphical and more descriptive format. Detailed statistical results are available from the authors upon request.

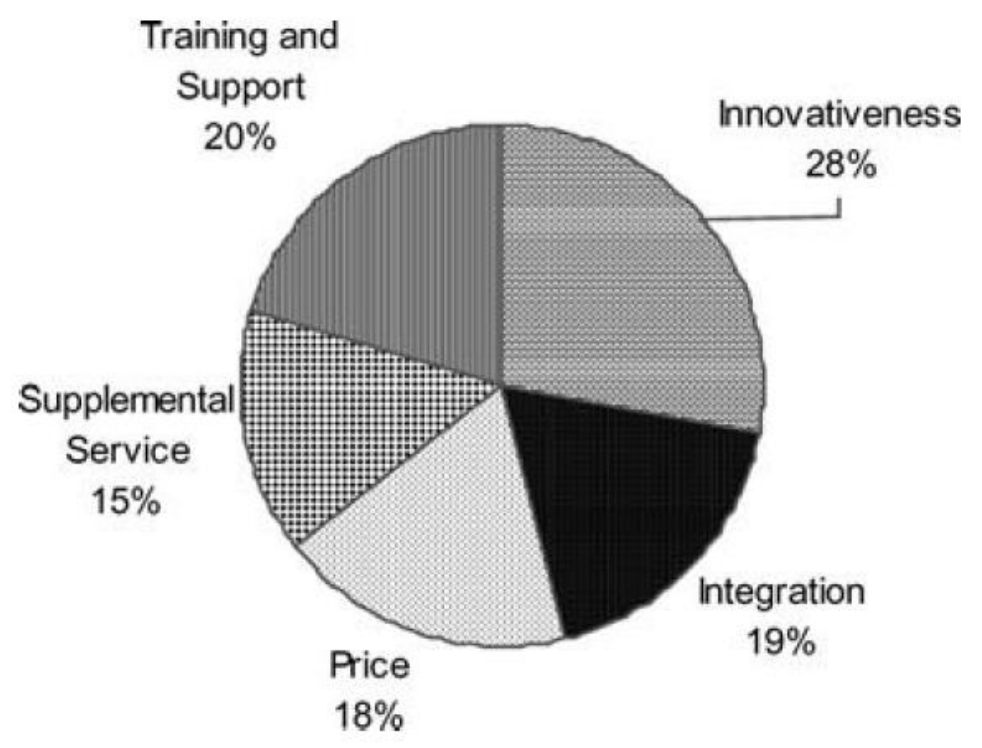

Figure 3: Relative main effects of experimental constructs.

Figure 3 shows the relative weight of each of the five constructs (innovativeness, integration, price, supplemental service, and training and support) in the supplier-selection process for all respondents. The relative sizes of the fractions represent the value of each construct (similar to the value-matrix presented in Table 1) and are derived from the main effects of the constituent attributes (the main effects of all attributes included within each construct were added together to get the composite score for each construct). The relative impact of innovativeness is highest (28\%), followed by relatively similar impact by training and support (20\%), integration (19\%), and price (18\%). The impact of supplemental service was lowest at $15 \%$.

Figure 4 shows the estimated relative $\beta$ weights rescaled between 0 and 1 representing the highest and lowest impact of each attribute. The relative weight for interoperability was the highest, and, for the sake of clarity, its value was scaled to 1.0, and all other numbers were relative to the highest score. Figure 4 shows that the second most important attribute was IT integration (.73) followed by training options (.68) and automation focus (.67). The attributes with the three lowest impacts were local sales support (.11), ease of system programming (.08), and product breadth (.07).

The relative $\beta$ weights for each attribute can be drilled down further to each level of each attribute. For the sake of illustration, we have plotted in Figure 5 relative $\beta$ weights for various levels of two attributes (cost optimization and industry-specific integration experience). 


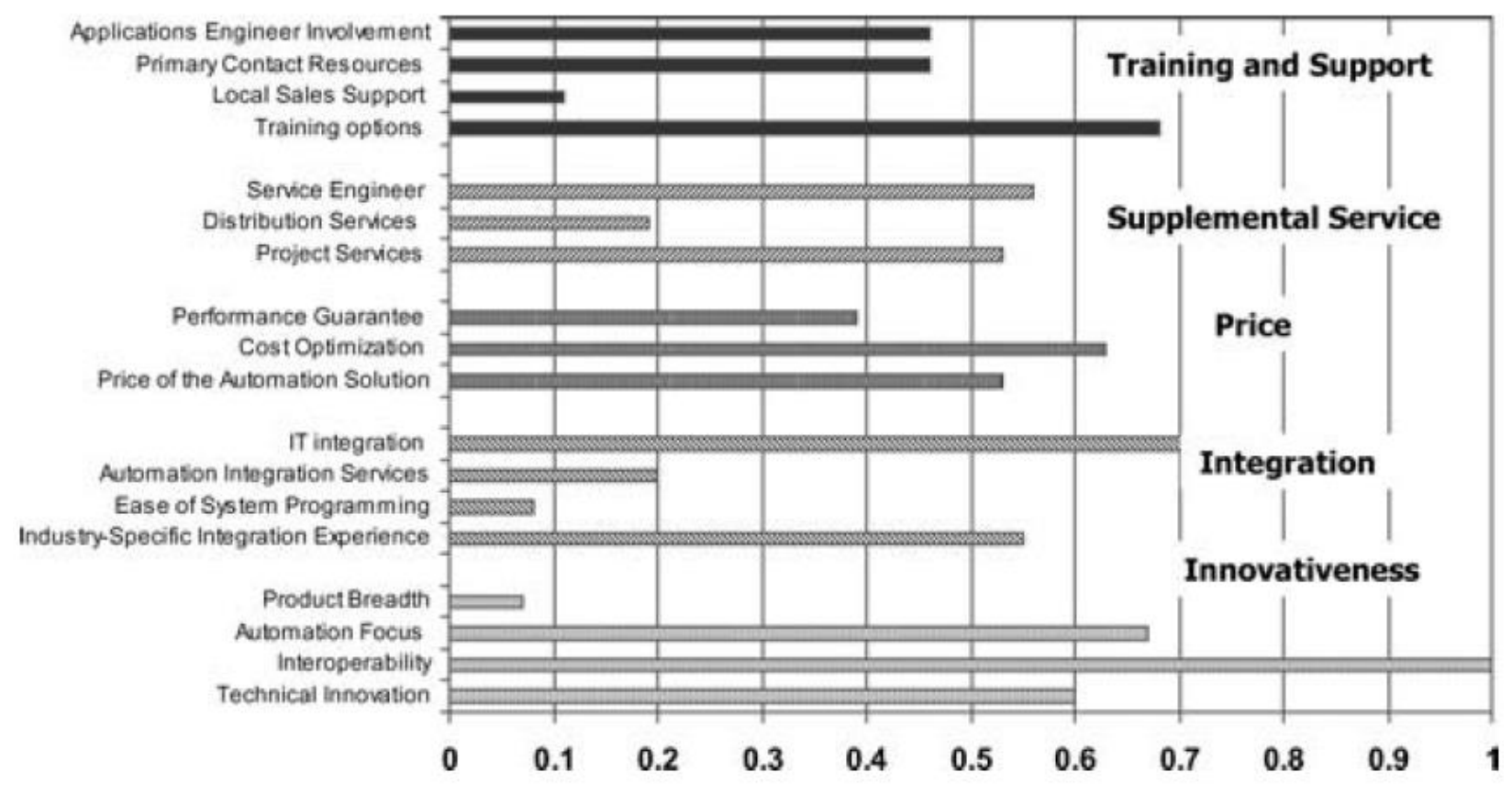

Figure 4: Relative main effects of determine attributes.

We noticed that guaranteed cost reduction was preferred compared to the other three alternatives (e.g., Supplier presents customer testimonials and estimated figures on proven cost reduction. No real data is presented). Similarly, the companies with proven functional but not industry specific experience are preferred to companies with industry-specific but not functional experience.
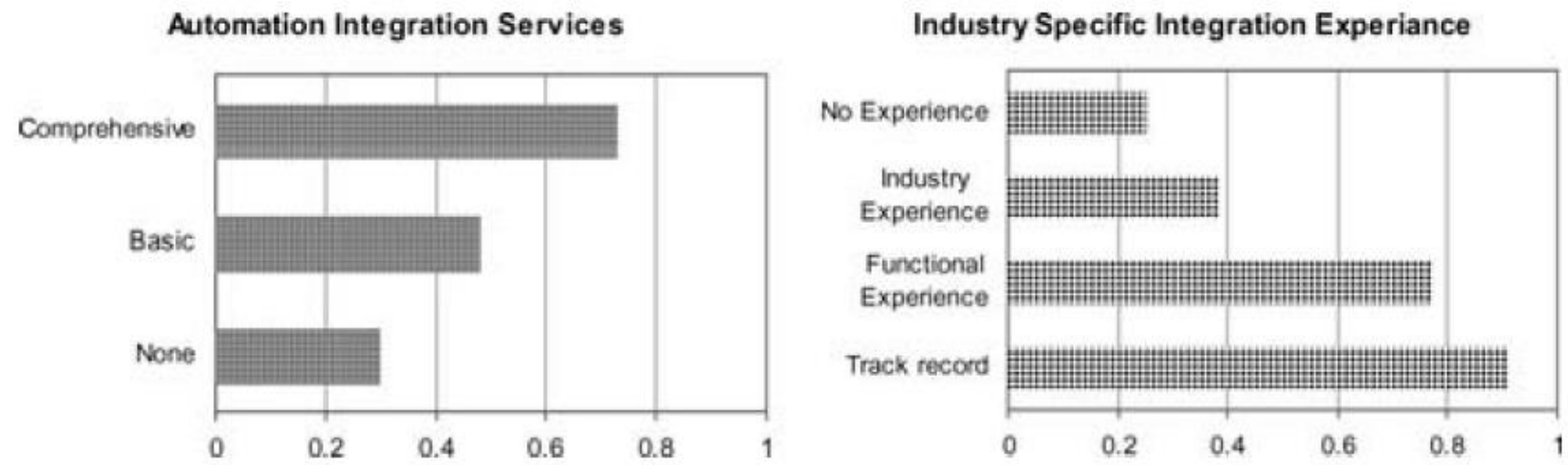

Figure 5: Relative main effects of attribute levels.

Intercepts in MNL models measure the impact of all unobserved attributes and, therefore, provide an assessment of switching inertia. A positive value of the intercept means that the respondents choose the new (or experimentally generated) supplier more often than choosing the current supplier. Similarly a negative intercept means that the current supplier was chosen more often than the new alternatives. In Figure 6, we present the value of 
switching inertia for each of the three market segments (pharmaceutical, chemical, and paper and pulp) along with the relative values of each of the five experimental constructs. The results show that switching inertia in pharmaceutical and chemical industries are quite high, whereas it is negligible within the paper-and-pulp industry.

The results also provide some interesting insights into challenger strategy. These can be examined at three levels, as illustrated below.

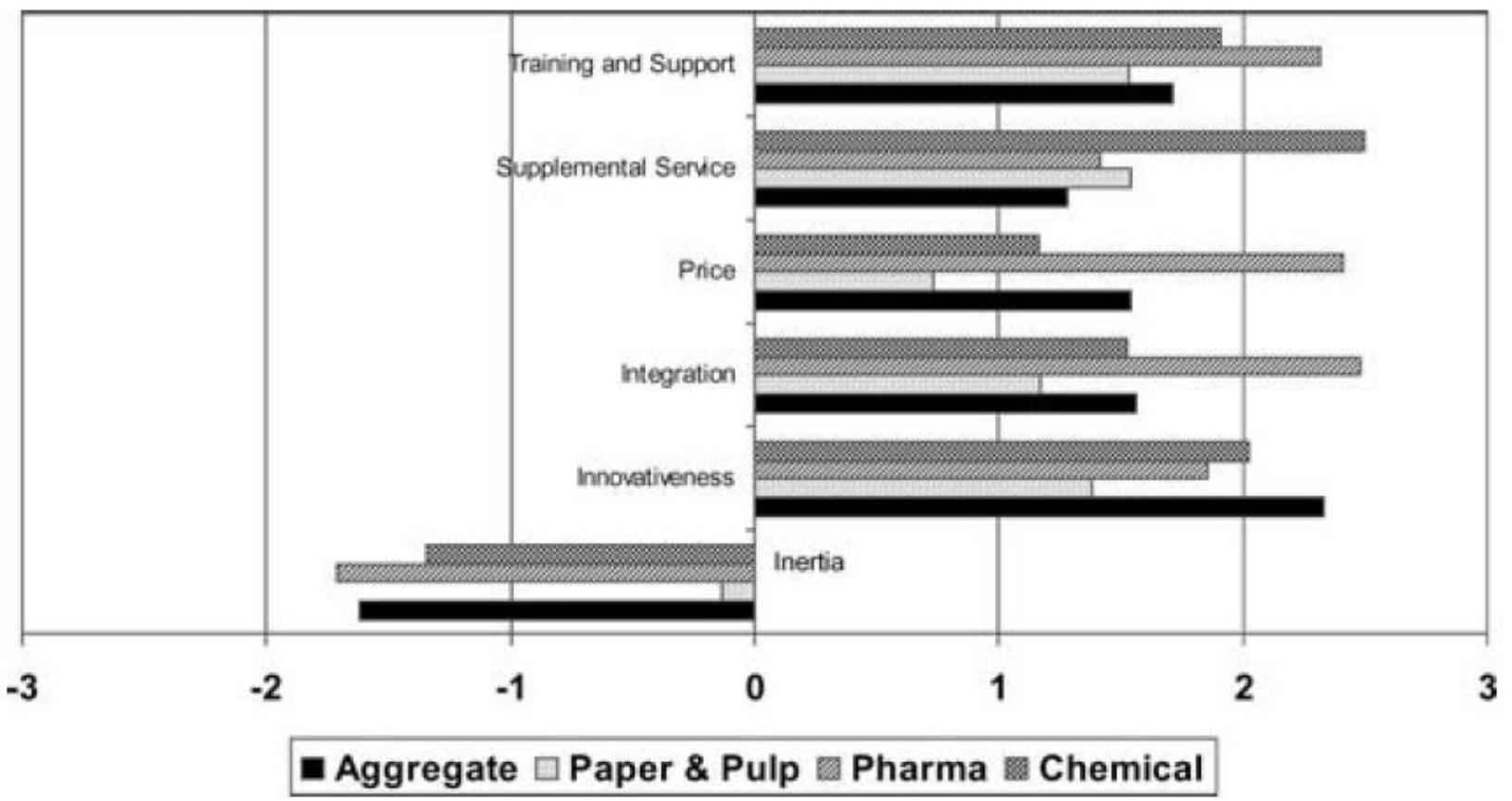

Figure 6: Relative main effects of experimental constructs across three industry sectors.

\section{Within Attribute Category}

Let us take any single category, for example, innovativeness, to demonstrate our argument. Note that, in the innovativeness category, interoperability is the most important attribute relative to the others (including the components of other attributes as well). On the other hand, product breadth has minimal impact on customer choice. Moreover, at only slightly more than half the level of interoperability, technical innovation is the second-least important attribute. Although conventional wisdom suggests that in technologically intensive industries innovations are an important source of competitive advantage, our results suggest that, to the extent that innovation and product development consume a fair amount of resources, a challenger emphasizing these attributes in the automation industry may be making wrong decisions. 


\section{Across Categories}

Now consider, for instance, the main attribute of supplemental service. Our results suggest that, among its component attributes, the provision of a technical-service engineer is what provides the customer with the most utility. Even if the challenger were able to embed a service engineer into the customer's facilities, the returns on doing so would be lower than those resulting from focusing on technical innovation (approximately the same utility as a service engineer), other things being equal (e.g., both attributes provided are addressed at the high-value end), because innovativeness as a main category has much greater salience (28\%) than supplemental services (15\%) in the buyer's value profile (see Figure 3). Note, however, that it is not just the value matrix but also how the incumbent is positioned within it that is of critical importance. The only condition in which there would be greater returns to a focus on a service engineer relative to innovation is if the incumbent provides a low level of service with respect to a service engineer and a high level of technical innovation. In such cases, other things being equal, investing in the former goes further in overcoming the negative effect of switching inertia and could compensate for the lower salience at the main attribute level. Therefore, the task for the challenger would be to examine various aspects of the buyer value profile and the incumbent's performance on these dimensions in order to determine where it should focus its efforts in constructing a superior value bundle.

\section{Across Industries}

The third important point of note is that buyer switching inertia varies across industries. For instance, one can see from Figure 6 that, even though the aggregate level of switching inertia is near 2, the paper-and-pulp industry has the lowest level of switching inertia and the pharmaceutical industry has the highest. This is understandable because the former is the most commodity-like and standardized of the three industries. Given that firms normally do not possess the resources to do all things at once, this has implications for the challenger regarding order of entry. Clearly, it would make more sense to attack the incumbent where switching inertia is the least, and through the process of serving this industry, build the capabilities and track record necessary to take on more difficult industries, especially because functional experience is more important than industry-specific experience.

\section{Discussion and Conclusion}

In our study, we demonstrate the existence of switching inertia and, as a result, of the competitive asymmetry between incumbents and challenger suppliers from a demand-side perspective. Of course, an additional and necessary consideration is the capability of the challenger to deliver its products and services with respect to those attributes that provide maximum potential to overcome buyer inertia and thus help outmaneuver the incumbent. We did not address this in our study because of our focus on the buyer perspective and demandside asymmetry. This asymmetry has a number of theoretical implications. First, our work complements extant work, in particular the RBV, in addressing the issue of competitive 
heterogeneity. The RBV emphasizes the question of why firms differ and competitive heterogeneity exists across rivals. In its explanation however, the RBV focuses on supply-side differences, that is, some firms have more superior attributes than others. Our work emphasizes competitive heterogeneity but develops the rationale from the demand side. That is, even if similar, incumbents and challengers are in asymmetric positions from the point of view of the buyer, thus requiring asymmetric (i.e., different) resource bundles to succeed. Of course, if firms differ due to demand asymmetry reasons and consequently concentrate on different attributes, then as a result of experience, path-dependence, and the like, this would ultimately also be reflected in superiority on the supply side. An integration of demand-and supply-side arguments would provide a more robust basis for explaining competitive heterogeneity.

Second, through our examination of demand asymmetry, we address a more fundamental issue. Given the existence of high switching inertia, what if there are inadequate returns to imitation? In such cases, even if challengers possess the capabilities to imitate the incumbent, the question arises as to whether they should do so. Such a question shifts the key issue from the ability to imitate (i.e., ability-based isolating mechanism) to the incentive to do so (i.e., willingness based isolating mechanism). This implies that, besides the inherent and quasi natural characteristic of resources in and of themselves, isolating mechanisms may also lie within the domain of management and managerial choice. This line of argument complements Oliver's (1997) argument that managers often may not be willing to imitate a rival's resources/capabilities for institutional reasons to do with legitimacy. In such a case, the isolating mechanisms would be of a self-imposed nature by would-be imitators. However, whereas Oliver distinguished and categorized ability and willingness-based isolating mechanisms on the basis of economic and normative rationality respectively, we have developed our arguments for both on the basis of economic rationality alone.

Clearly, if competitive heterogeneity is present even when supply-side ability based isolating mechanisms are weak, this indicates that other forces that occasion competitive heterogeneity are present (Hoopes et al., 2003). Our demonstration of buyer switching inertia highlights an important factor in the rivalry between incumbents and challengers. That is, the special demands of downstream buyers on challengers may themselves cause an isolating mechanism to prevent challengers from pure imitation (Adner \& Zemsky, 2006). By proposing a willing-based isolating mechanism from the demand side, we are by no means conflicting with the ability-based ones from the supply-side perspective. As we suggest above, the two are complementary to one another in directing firms' resource allocation and deployment decisions. That is, they co-determine the competitive heterogeneity phenomenon in an industry.

Third, our study also expands Porter's (1996) argument on operational effectiveness versus strategic position in interfirm rivalry. By experimentally observing the competitive rivalry in the automation industry, we empirically confirm, from the challenger's point of view in 
particular, that in the presence of buyer switching inertia challengers will be better off by establishing unique strategic positions than pursuing operational effectiveness. In this regard, even though a challenger's value-creation capabilities may not be sufficient to overcome the overall switching inertia, variation across segments in the level of switching inertia, as well as in the value distribution across the various attributes, provides opportunities for the challengers to selectively attack the incumbent.

This has direct managerial implications. The following steps can help challengers establish better strategic positions. First, challengers must identify buyers' value profile, with the knowledge of buyers' relatively important value dimensions and switching inertia. When possible, challengers also must understand the differences between buyer groups in terms of value dimensions and switching inertia. Second, challengers must examine the incumbent's value-creation capabilities and accordingly map the incumbent's capability onto the buyers' value profile. Third, challengers must evaluate whether the potential value-creation space that is not being currently occupied by the incumbent is large enough to overcome buyer switching inertia. Fourth, challengers must assess whether they are able and willing to put forward an alternative value bundle to buyers to attack the incumbent. While it is beyond the scope of this article, we would like to emphasize that, based on the results of this study, a relatively easy-touse managerial decision-support simulation can be constructed to assist executives in their supplier-selection deliberations, considering switching inertia and relative strengths and weaknesses of the incumbent and challenger suppliers. Examples of similar decision-support tools based on DCA have been presented earlier by Verma et al. (1999), Verma et al. (2001), and Pullman and Moore (1999). Indeed, we developed a decision support tool for the organization that sponsored this research and paid for all of the data collection expenses. We contacted a senior executive at the sponsoring organization who confirmed that the results of this study and the corresponding decision-support tool are being used routinely in the deliberations of the supplier evolution and selection process.

This article is not without its limitations. For instance, in the empirical testing, we did not examine the effect of market growth on challenger strategy. Industrial automation is an industry with relatively less sudden technological changes, which may result in high switching inertia. This also leads to the broader issue of generalizability. Because our study was in a capital- and technology-intensive context and in a somewhat stable industry, it would be interesting to determine whether it generalizes to other contexts. This would be a useful area for further research. Also, our article is based on an economic logic, but certainly there are other noneconomic reasons why a firm might not duplicate its rivals' resources/capabilities. However, these are outside of the scope of this article.

In conclusion, this work makes a number of contributions to the strategic management literature. First, through examining switching inertia, the article affirms the existence of demand-side asymmetry in determining competitive heterogeneity across rivals in an industry. The demand-side perspective has been relatively neglected in much of the literature and 
usefully complements the traditional supply-side approach in providing a more robust understanding of isolating mechanisms and competitive heterogeneity. Second, we introduce DCA into the field of strategic management to better examine buyer preferences. This may provide a potentially useful empirical tool for future research in this and other related areas. By demonstrating demand-side asymmetry between incumbents and challengers as a result of buyer switching inertia, we hope to arouse the awareness of scholars on this issue and stimulate further research in this direction. [Received: April 2006. Accepted: September 2006.]

\section{References}

Adner, R., \& Levinthal, D. (2001). Demand heterogeneity and technology evolution: Implications for product and process innovation. Management Science, 47, 611-628.

Adner, R., \& Zemsky, P. (2006). A demand-based perspective on technology lifecycles. Strategic Management Journal, 27, 215-239.

Anderson, N. (1971). Integration theory and attitude change. Psychological Review, 78(3), 171206.

Ansari, A., \& Modarress, B. (1980). JIT purchasing as a quality and productivity center. International Journal of Production Research, 26(1), 19-26.

Ansari, A., \& Modarress, B. (1986). Just-in-time purchasing: Problems and solutions. Journal of Purchasing and Materials Management, 22(2), 11-15.

Barbarosoglu, G., \& Yazgac, T. (1997). An application of the analytic hierarchy process to the supplier selection problem. Production \& Inventory Management Journal, 38(1), 14-21.

Barney, J. (1991). Firm resources and sustained competitive advantage. Journal of Management, 17(1), 99-120.

Basnet, C., \& Leung, J. (2005). Inventory lot-sizing with supplier selection. Computers \& Operations Research, 32(1), 1-14.

Ben-Akiva, M., \& Lerman, S. (1991). Discrete choice analysis. Cambridge, MA: MIT Press.

Benton, W. C., \& Krajewski, L. (1990). Vendor performance and alternative manufacturing environments. Decision Sciences, 21, 403-415.

Bernard, P. (1989). Managing vendor performance. Production \& Inventory Management Journal, 30(1), 1-7.

Bettman, J. R., Capon, N.,\&Lutz, R. J. (1975). Cognitive algebra in multi attribute models. Journal of Marketing Research, 12, 151-164. 
Bhutta, K. S., \& Huq, F. (2002). Supplier selection problem: A comparison of the total cost of ownership and analytical hierarchy process approaches. Supply Chain Management, 7(3/4), 126-136.

Braglia, M. (2000). A quality assurance-oriented methodology for handling tradeoffs in supplier selection. International Journal of Physical Distribution \& Logistics Management, 30(1/2), 96-111.

Brewer, A. M., Button, K. J., \& Hensher, D. A. (2001). Handbook of logistics and supply chain management. New York: Pergamon.

Browning, J. M., Zabriskie, N. B., \& Huellmantel, A. B. (1983). Strategic purchasing planning. Journal of Purchasing and Materials Management, 19(1), 19-24.

Burton, T. T. (1988). JIT/Repetitive sourcing strategies: Tying the knot with your suppliers. Production \& Inventory Management, 29(4), 38-41.

Cakravastia, A., \& Takahashi, K. (2004). Integrated model for supplier selection and negotiation in a make-to-order environment. International Journal of Production Research, 42, 4457-4474.

Cardozo, R., \& Cagley, J. (1971). Experimental study of industrial buyer behavior. Journal of Marketing Research, 8, 329-334.

Carter, C. R., \& Jennings, M. M. (2004). The role of purchasing in corporate social responsibility: A structural equation analysis. Journal of Business Logistics, 25(1), 145-186.

Caves, R., \& Porter, M. (1977). From entry barriers to mobility barriers. Quarterly Journal of Economics, 91(2), 241-261.

Crama, Y., Pascual, J., \& Torres, A. (2004). Optimal procurement decisions in the presence of total quantity discounts and alternative product recipes. European Journal of Operational Research, 159, 364-378.

Chapman, S. (1993). Just-in-time supplier inventory: An empirical implementation model. International Journal of Production Research, 27, 1993-2007.

Chan, F. (2003). Interactive selection model for supplier selection process: An analytical hierarchy process approach. International Journal of Production Research, 41, 35493579.

Chan, F.,\&Chan, H. (2004). Development of the supplier selection model-A case study in the advanced technology industry. Proceedings of the Institution of Mechanical Engineers Part B-Engineering Manufacture, 218, 1807-1824.

Chen, M. -J. (1996). Competitor analysis and interfirm rivalry: Toward a theoretical integration. Academy of Management Review, 21(1), 100-134. 
Cho, D., Kim, D., \& Rhee, D. (1998). Latecomer strategies: Evidence from the semiconductor industry in Japan and Korea. Organization Science, 9, 498-505.

Choi, T., \& Hartley, J. (1996). An exploration of supplier selection practices across the supply chain. Journal of Operations Management, 14, 333-343.

Choy, K., Lee, W., \& Lo, V. (2003). An intelligent supplier relationship management system for selecting and benchmarking suppliers. International Journal of Technology Management, 26, 717-740.

Choy, K., Lee,W., Lau, H., Lu, D.,\&Lo,V. (2004). Design of an intelligent supplier relationship management system for newproduct development. International Journal of Computer Integrated Manufacturing, 17, 692-715.

D’Aveni, R. A. (1994). Hypercompetition. New York: Free Press.

Degraeve, Z., Labro, E., \& Roodhooft, F. (2005). Constructing a total cost of ownership supplier selection methodology based on activity-based costing and mathematical programming. Accounting and Business Research, 35(1), 3-27.

Dempsey,W. (1978). Vendor selection and the buying process. Industrial Marketing Management, 7(4), 257-267.

Dickson, G. (1966). An analysis of vendor selection systems and decisions. Journal of Purchasing, 2(1), 5-17.

Dyer, J.,\&Singh, H. (1998). The relational view: Cooperative strategy and sources of interorganizational competitive advantage. Academy of Management Review, 23, 660-679.

Eltantawy, R. A., Sharland, A., \& Giunipero, L. C. (2003). The impact of cycle time on supplier selection and subsequent performance outcomes. Journal of Supply Chain Management, 39(3), 4-12.

Fine, C. (1998). Clock speed: Winning industry control in the age of temporary advantage. Reading, MA: Perseus Books.

Flynn, B., Schroeder, R., \& Sakakibara, S. (1994). A framework for quality management research and an associated measurement instrument. Journal of Operations Management, 11, 339-366.

Gonz'alez, M., Quesada, G., \& Mora Monge, C. (2004). Determining the importance of the supplier selection process in manufacturing: A case study. International Journal of Physical Distribution \& Logistics Management, 34, 492-504.

Guadagni, P., \& Little, J. (1983). A logit model of brand choice calibrated on scanner data. Marketing Science, 2(3), 203-237. 
Green, P.,\&Krieger, A. (1996). Individualized hybrid models for conjoint analysis. Management Science, 42, 850-867.

Green, P., \& Srinivasan, V. (1990). Conjoint analysis in marketing: New developments with implications for research and practice. Journal of Marketing, 54(4), 3-19.

Gulati, R. (1995). Does familiarity breed trust? The implications of repeated ties for contractual choice in alliances. Academy of Management Journal, 38(1), 85-112.

Hall, D., \& Braithwaite, A. (2001). The development of thinking in supply chain and logistics management. In A. M. Brewer, K. J. Button, \& D. A. Hensher (Eds.), Handbook of logistics and supply chain management. New York: Pergamon.

Hanfield, R., \& Nichols, E., Jr. (1999). Introduction to supply chain management. Upper Saddle River, NJ: Prentice Hall.

Hensher, D., \& Johnson, L. (1980). Applied discrete choice modelling. London: Croom-Helm.

Hirakubo, N., \& Kublin, M. (1998). The relative importance of supplier selection criteria: The case of electronic components. International Journal of Purchasing \& Materials Management, 34(2), 19-24.

Hoopes, D., Madsen, T., \& Walker, G. (2003). Guest editors' introduction to the special issue: Why is there a resource-based view? Toward a theory of competitive heterogeneity. Strategic Management Journal, 24, 889-902.

Ittner, C., \& Larcker, D. (1999). Supplier selection, monitoring practices, and firm performance. Journal of Accounting \& Public Policy, 18, 253-281.

Jackson, G. (1983). Just-in-time production: Implications for logistics managers. Journal of Business Logistics, 4(2), 1-19.

Kaplan, S., \& Sawhney, M. (2000). e-hubs: The new B2B marketplaces. Harvard Business Review, 78(3), 97-103.

Karpak, B., Birsen, K., Rammohan, R., \& Kumcu, E. (1999). Multi-objective decision-making in supplier selection: An application of visual interactive goal programming. Journal of Applied Business Research, 15(2), 57-71.

Kraljic, P. (1983). Purchasing must become supply management. Harvard Business Review, 61(5), 109-117.

Kannan, V., \& Tan, K. (2002). Supplier selection and assessment: Their impact on business performance. Journal of Supply Chain Management, 38(4), 11. 
Lambert, D., \& Adams, R. (1997). Supplier selection criteria in the healthcare industry: A comparison of importance and performance. International Journal of Purchasing \& Materials Management, 33(1), 16-22.

Lieberman, M.,\& Montgomery, D. (1988). First-mover advantages. Strategic Management Journal, 9(41), 41-58.

Lin, C., Chow, W., Madu, C., Kuei, C., \& Yu, P. (2005). A structural equation model of supply chain quality management and organizational performance. International Journal of Production Economics, 96, 355-365.

Louviere, J. (1988). Analyzing decision making: Metric conjoint analysis. Newbury , CA: Sage.

Louviere, J., Hensher, D., \& Swait, J. (2001). Stated preference methods: Analysis and application. Cambridge, UK: Cambridge University Press.

Louviere, J., \& Timmermans, H. (1990). Stated preference and choice models applied to recreation research: A review. Leisure Science, 12(1), 9-32.

Louviere, J., \& Woodworth, G. (1983). Design and analysis of simulated consumer choice or allocation experiments: An approach based on aggregate data. Journal of Marketing Research, 20, 350-367

Lynch, J., Marmorstein, H., \& Weigold, M. (1988). Choices from sets including remembered brands: Use of recalled attributes and prior overall evaluations. Journal of Consumer Research, 15(2), 169-184.

Masella, C., \& Rangone, A. (2000). A contingent approach to the design of vendor selection systems for different types of co-operative customer/supplier relationships. International Journal of Operations and Production Management, 21(1), 70-84.

McFadden, D. (1986). The choice theory approach to market research. Marketing Science, 5(4), 275-297.

Monczka, R., Giunipero, L., \& Reck, R. (1981). Perceived importance of supplier information. Journal of Purchasing and Materials Management, 17(1), 21-29.

Narasimhan, R., Talluri, S., \& Mahapatra, S. (2006). Multi-product, multicriteria model for supplier selection with product life cycle considerations. Decision Sciences, 37, 577-604.

Oliver, C. (1997). Sustainable competitive advantage: Combining institutional and resourcebased views. Strategic Management Journal, 18, 697-713.

Patton, W. III. (1996). Use of human judgment models in industrial buyers' vendor selection decisions. Industrial Marketing Management, 25(2), 135-149. 
Patton, W. III. (1997). Individual and joint decision-making in industrial vendor selection. Journal of Business Research, 38(2), 115-122.

Pearn, W., Wu, C., \& Lin, W. (2004). Procedure for supplier selection based on Cpm applied to super twisted nematic liquid crystal display processes. International Journal of Production Research, 42, 2719-2734.

Pearson, J., \& Ellram, L. (1995). Supplier selection and evaluation in small versus large electronics firms. Journal of Small Business Management, 33(4), 53-65.

Petroni, A., \& Braglia, M. (2000). Vendor selection using principle components analysis. Journal of Supply Chain Management, 36(2), 63-69.

Porter, M. (1991). Towards a dynamic theory of strategy. Strategic Management Journal, 12(Special Issue), 95-117.

Porter, M. (1996). What is a strategy? Harvard Business Review, 74(6), 61-78.

Pullman, M., Verma, R., \& Goodale, J. (2001). Service design and operations strategy formulation in multicultural markets. Journal of Operations Management, 19, 239-254.

Roodhooft, F., \& Konings, J. (1997). Vendor selection and evaluation. European Journal of Operational Research, 96(1), 97-102.

Rosenthal, E., \& Zydiak, J. (1995). Vendor selection with bundling. Decision Sciences, 26, 35149.

Rumelt, R. (1984). Toward a strategic theory of the firm. In R. Lamb (Ed.), Competitive strategic management. Englewood Cliffs, NJ: Prentice-Hall, 556-570.

Rumelt, R. (1995). Inertia and transformation. In C. A. Montgomery (Ed.), Resource-based and evolutionary theories of the firm. Boston: Kluwer Academic Publishers, 101-132.

Sarkis, J., \& Semple, J. (1999). Vendor selection with bundling: A comment. Decision Sciences, $30,265-271$.

Sheth, J. (1973). A model for industrial buyer behavior. Journal of Marketing, 37(4), 50-56.

Simchi-Levi, D., Kaminsky, P.,\&Simchi-Levi, E. (2000). Designing and managing the supply chain. Boston: McGraw-Hill.

Shamsie, J., Phelps, C., \& Kuperman, J. (2004). Better late than never: A study of late entrants in household electrical equipment. Strategic Management Journal, 25, 69-84.

Swait, J., \& Louviere, J. (1993). The role of the scale parameter in the estimation and comparison of multinomial logit models. Journal of Marketing Research, 30, 305-314. 
Swift, C. (1995). Preferences for single sourcing and supplier selection criteria. Journal of Business Research, 32(2), 105-111.

Talluri, S.,\& Narasimhan, R. (2005). A methodology for supply base optimization. IEEE Transactions on Engineering Management, 52(1), 130-139.

Talluri, S., \& Narasimhan, R. (2004). A methodology for strategic sourcing. European Journal of Operations Research, 154(1), 236-250.

Treleven, M. (1987). Single sourcing: A management tool for the quality supplier. Journal of Purchasing and Materials Management, 23(1), 19-24.

Tseng, Y., \& Lin, Y. (2005). A model for supplier selection and tasks assignment. Journal of American Academy of Business, 6(2), 197-207.

Verma, R., Iqbal, Z., \& Plaschka, G. (2004). Choice drivers and switching inertia in e-financial services. California Management Review, 46(4), 43-68.

Verma, R., Thompson, G., \& Louviere, J. (1999). Configuring service operations based on customer needs and preferences. Journal of Service Research, 1(3), 262-274.

Verma, R., Thompson, G., Moore, W., \& Louviere, J. (2001). Effective design of products/services: An approach based on integration of marketing and operations. Management decisions. Decision Sciences, 32, 165-193.

Verma, R., \& Pullman, M. (1998). An analysis of the supplier selection process. Omega, 26, 739750.

Verma, R., \& Plaschka, G. (2005). Predicting customer choices. MIT Sloan Management Review, 47(1), 7-10.

Vonderembse, M., \& Tracey, M. (1999). The impact of supplier selection criteria and supplier involvement on manufacturing performance. Journal of Supply Chain Management, 35(3), 33-39.

Vokurka, R., \& Choobineh, J. (1996). A prototype expert system for the evaluation and selection of potential suppliers. International Journal of Operations \& Production Management, 16(2), 106-127.

Wagner, J., Ettenson, R., \& Parrish, J. (1989).Vendor selection among retail buyers: An analysis by merchandise division. Journal of Retailing, 65(1), 58-77.

Weber, C., \& Current, J. (1993). A mulitobjective approach to vendor selection. European Journal of Operational Research, 68(2), 173-184.

Weber, C., Current, J.,\& Benton, W. (1991).Vendor selection criteria and methods. European Journal of Operational Research, 50(1), 2-18. 
Wernerfelt, B. (1984). A resource-based view of the firm. Strategic Management Journal, 5 , 171-180.

Williamson, O. (1985). The economic institutions of capitalism: Firms, markets, relational contracting. New York: Free Press.

Yan, J., Chaudhry, P., \& Chaudhry, S. (2003). A model of a decision support system based on case-based reasoning for third-party logistics evaluation. Expert Systems, 20(4), 196207.

\section{Author Bios}

Sali $\mathbf{L} i$ is a PhD candidate in strategy at the University of Utah. His research interests include resource abandonment, technology management, firm heterogeneity, and entrepreneurship. He has published in journals such as Journal of International Business and Academy of Management Best Paper Proceedings, among others. He is a member of the Academy of Management, Academy of International Business, and Strategic Management Society.

Anoop Madhok is professor of strategy at the Schulich School of Business, York University, Toronto and visiting professor, Department of Public Administration and Organization Science, Vrije University, Amsterdam. He obtained his PhD in 1993 from McGill University, Montreal (major in strategy and minor in international political economy) and an MA in international studies from Johns Hopkins University (majors in international economics and social change \& development). Professor Madhok's research interests span strategy and international management and include topics such as multinational firm strategy, foreign market entry, strategic alliances, trust and interfirm collaboration, and the theory and boundaries of the firm. His work has been published in the Academy of Management Journal, Strategic Management Journal, Organization Science, Journal of International Business Studies, and Management International Review, among many others, as well as in a variety of books. He serves on the editorial review board of Strategic Management Journal, Journal of International Business Studies, Journal of Management, Journal of International Management, and Journal of World Business.

Gerhard R. Plaschka is associate professor in strategy and venture management in the Kellstadt Graduate School of Business at DePaul University, Chicago. He obtained his PhD at the Vienna University of Economics and Business Administration, Austria. His primary research interests are demand-side-based strategy issues within highly complex, emerging and mature industrial product and service markets. His collaboration with senior executives in Global 500 companies and distinguished researchers has enabled him to establish a distinctive demand-side driven understanding of corporate strategy using choice modeling methods. He has published in MIT Sloan Management Review, California Management Review, Cornell Hotel and Restaurant Administration Quarterly, Entrepreneurship Theory and Practice, and Zeitschrift fuer betriebswirtschaftliche Forschung (ZbfF). 
Rohit Verma is associate professor of service operations management at the School of Hotel Administration, Cornell University. He is currently on leave from David Eccles School of Business, University of Utah, where he holds the position of George S. Eccles Professor of Management. His research has appeared in California Management Review, Cornell Quarterly, Journal of Operations Management, Journal of Product Innovation Management, Journal of Service Research, MIT Sloan Management Review, Production and Operations Management, and other journals. He serves as an associate editor of Journal of Operations Management and Decision Sciences, senior editor of Production and Operations Management, and editorial board member of Journal of Service Research and Cornell Quarterly. He also served as guest editor for five issues of Journal of Operations Management on topics related to effective management of service businesses. 